\title{
ANÁLISE DAS RESPOSTAS COMPORTAMENTAISAO CÂNCER DE MAMA UTILIZANDO O MODELO ADAPTATIVO DE ROY
}

\author{
Analysis of behavioural responses to breast cancer using the Roy adaptation model \\ Análisis de las respuestas comportamentales al cáncer de mama a través del modelo \\ adaptativo de Roy
}

Letícia Rosa Santos ${ }^{1}$

Glaucia Batista Tavares²

Paula Elaine Diniz dos Reis ${ }^{3}$

\section{RESUMO}

0 estudo analisa as respostas comportamentais das mulheres durante o tratamento do câncer de mama utilizando o Modelo de Adaptação de Roy. Estudos demonstram que o câncer e sua terapêutica podem gerar estímulos que irão interferir na sexualidade. Conhecer os mecanismos de enfrentamento destas mulheres deve ser uma preocupação dos profissionais que prestam assistência, para que se possa oferecer o cuidado integral. Trata-se de pesquisa qualitativa na qual foi realizada entrevista semiestruturada com cinco mulheres sexualmente ativas. Foram identificados problemas de adaptação nos modos relacionados ao autoconceito, desempenho de papéis e interdependência. Contudo, essas mulheres puderam superar tal situação e melhorar a adaptação à sua nova condição. Conclui-se que a utilização do modelo de adaptação de Roy foi apropriada, pois permitiu apreender as alterações relacionadas aos modos adaptativos e visualizar de forma concreta quais os focos para as intervenções de enfermagem.

Palavras-chave: Neoplasias de mama. Teoria de enfermagem. Modelos de enfermagem. Adaptação.

\begin{abstract}
The study analyzes the behavioural responses of women during treatment for breast cancer using the Roy Adaptation Model. Studies show that cancer and its treatment can generate stimuli that will interfere in the sexuality. Knowing the mechanisms these women face must be a concern of the healthcare professionals, so that comprehensive care can be provided. The study involved qualitative research where semi-structured interviews were conducted with five sexually active women. Problems were identified in the modes of adaptation related to self-concept, role playing, and interdependence. These women were nevertheless able to overcome such situations and improve adaptation to their new condition. It was concluded that use of the Roy Adaptation Model was appropriate, making it possible to grasp the changes related to modes of adaptation, and thus enabling the foci of nursing interventions to be concretely visualized.
\end{abstract}

Keywords: Breast Neoplasms. Nursing Theory. Models, Nursing. Adaptation.

\section{Resumen}

El estudio examina el uso del Modelo de Adaptación de Roy en la comprensión de las respuestas de comportamiento de las mujeres durante el tratamiento del cáncer de mama. Los estudios demuestran que el cáncer y su tratamiento pueden crear incentivos que puedan interferir con la sexualidad. Conocer a los mecanismos de supervivencia de estas mujeres debe ser una preocupación de los profesionales que prestan asistencia para que se pueda ofrecer una atención integral. Se trata de una investigación cualitativa llevada a cabo a partir de entrevistas semestructuradas con cinco mujeres sexualmente activas. Se identificaron problemas en las modalidades de adaptación relacionadas con el concepto de sí mismo, el juego de roles y la interdependencia. Sin embargo, estas mujeres pudieron superar tal situación y mejorar la adaptación a su nueva condición. Se concluye que el uso del modelo de adaptación de Roy era adecuado, teniendo permitido comprender los cambios relacionados con los modos de adaptación, lo que permite la utilización de un enfoque concreto de las intervenciones en enfermería.

Palabras clave: Neoplasias de la Mama. Teoría de Enfermería. Modelos de Enfermería. Adaptación.

\footnotetext{
Doutoranda do curso de Pós-Graduação em Enfermagem da Universidade de Brasília- UnB. Bolsista CAPES. Araguari-MG. Brasil. E-mail: tenenteleticia@yahoo.com.br; ${ }^{2}$ Enfermeira, Sargento Enfermeira do Hospital de Força Aérea de Brasília. Brasilia-DF. Brasil. E-mail: oncoglau@yahoo.com.br; ${ }^{3}$ Doutora em Enfermagem, Docente do Departamento de Enfermagem da Faculdade de Ciências de Saúde da Universidade de Brasília - UnB. Brasilia DF. Brasil. E-mail: pdinizreis@yahoo.com
} 


\section{INTRODUÇÃO}

0 câncer de mama é uma patologia de alta incidência na atualidade, afetando principalmente o gênero feminino. Segundo dados do Instituto Nacional de Câncer - INCA, é o segundo tipo de câncer mais frequente no mundo e o mais comum entre mulheres. Anualmente, cerca de $23 \%$ dos casos novos de câncer diagnosticados em mulheres são de mama. As estimativas para novos números de casos em 2012 são de 52.680, atingindo cerca de 52 a cada 100 mil mulheres ${ }^{1}$.

Apesar de a idade avançada ser considerada fator de risco e a incidência crescer progressivamente após 35 anos, os casos de câncer de mama em pacientes jovens chama atenção especialmente por estar associado a um pior prognóstico quando comparado com outras faixas etárias; a mortalidade é de $46,9 \%$ para as pacientes com menos de 40 anos e de $26,9 \%$ para as acima desta idade?

Portanto, é importante considerar esse fato, pois a submissão ao tratamento de neoplasia mamária altera as atividades rotineiras dessas mulheres e afeta sua dinâmica social e emocional.

Considerando-se que a sexualidade humana tem dimensões biopsicossociais, inerentes a cada indivíduo no decorrer do ciclo vital, e que está relacionada com a qualidade de vida, esta deve ser abordada na assistência com a mesma relevância de outros aspectos afetados, tendo em vista a assistência integral ao paciente. Estudos demonstram que 0 câncer e sua terapêutica podem comprometer um ou mais sistemas no organismo e interferir na sexualidade. Conhecer as características dessa interferência deve ser preocupação dos profissionais que prestam assistência a essas mulheres, para que se possa oferecer cuidado integral e personalizado ${ }^{3,4}$. Para tanto, faz-se necessário que os profissionais realizem uma escuta ativa dessas mulheres e seus familiares de modo a conhecer seus sentimentos e experiências relativas ao processo vivenciado.

Podemos observar que embora um indivíduo seja submetido a uma mesma situação, a sua resposta pode ser variada em relação ao outro, a depender de sua personalidade e vivência, dando origem a diferentes respostas comportamentais. Assim, é possível afirmar que o ser humano tem capacidade adaptativa diante dos enfrentamentos gerados pelas situações de saúde-doença; neste estudo, o câncer foi a doença eleita enquanto patologia principal para avaliação de tais respostas.

Visualizando o cenário do câncer de mama sobre os aspectos listados acima, definimos a visão de mundo que irá nortear a assistência a ser prestada. Dentre as teorias e modelos propostos para a enfermagem, o Modelo de Adaptação de Roy, escolhido para este estudo, possibilita de forma eficaz a análise da situação e a proposição de uma assistência qualificada.

Neste estudo, portanto, serão apresentadas reflexões referentes ao processo adaptativo vivenciado pelas mulheres, os fatores que interferem ou contribuem para uma adaptação e onde a enfermagem pode atuar para facilitar tal processo adaptativo. Dessa forma, esta pesquisa tem como objetivo analisar as percepções das mulheres com câncer de mana sobre a sua sexualidade a partir da perspectiva do Modelo de Adaptação de Roy

\section{METODOLOGIA}

Trata-se de estudo qualitativo descritivo que deseja identificar as respostas comportamentais que o câncer de mama traz na vida das mulheres. Os sujeitos selecionados foram mulheres sexualmente ativas com idade entre 25 e 50 anos que tiveram diagnóstico de câncer de mama e realizaram tratamento com quimioterapia, radioterapia e/ou cirurgia, em um Hospital Público de Brasília, Distrito Federal.

A coleta de dados foi realizada por meio de entrevistas semiestruturadas, gravadas. As entrevistas foram realizadas com cinco pacientes em locais preestabelecidos, de fácil acesso para as entrevistadas e que permitia-lhes privacidade e conforto. Antes de sua realização, as pacientes foram informadas sobre o estudo, e, depois de sanadas suas dúvidas, assinaram o Termo de Consentimento Livre e Esclarecido, conforme recomenda a Resolução 196/96. Também como versa a resolução, o presente estudo foi aprovado pelo Comitê de Ética em Pesquisa da UNIEURO sob o protocolo 017/2009. A identificação dos sujeitos se deu por letras e números de forma a manter seu anonimato. De forma a preservar este mesmo princípio, falas que poderiam vir identificar claramente os sujeitos foram retiradas da análise.

As entrevistas foram lidas repetidas vezes como mecanismo para compreendê-las. Na interpretação dos resultados, foram procurados os significados dos depoimentos, utilizando-se para tanto o Modelo da Adaptação de Roy ${ }^{5}$ e a literatura pertinente ao tema. Assim, as ideias foram agrupadas em temáticas de acordo com os modos de adaptação de Roy sendo elencados nos relatos das entrevistas os modos autoconceito, desempenho de papéis e interdependência.

\section{RESULTADOS E DISCUSSÃO}

A teoria do Modelo de Adaptação de Roy pode ser considerada uma grande teoria. Foi desenvolvida por Sister Callista Roy ${ }^{5}$, enfermeira e teórica de enfermagem, que a partir de sua experiência como enfermeira pediátrica, admitiu que 0 conceito de adaptação pudesse se constituir como um eixo orientador para a prática de enfermagem.

Roy considera como metaparadigmas em seu modelo: pessoa, ambiente, saúde e meta de enfermagem. A pessoa no Modelo de Adaptação de Roy é um ser social, mental, espiritual e físico, afetado por estímulos do ambiente. É um sistema adaptativo holístico, em contínua interação com o meio ambiente mutante. Os comportamentos que são respostas diante de tais estímulos podem ser classificados como reações adaptativas 
ou reações ineficientes. Esses comportamentos derivam-se dos mecanismos regulador e cogniscente, os quais trabalham no âmbito de quatro modos adaptativos: função fisiológica, autoconceito, função de papéis e interdependência. 0 ambiente é compreendido como um conjunto de forças internas e externas em um estado de contínua mudança. A saúde é a capacidade do indivíduo de adaptar-se à mudança no ambiente. A enfermagem é a arte humanitária e ciência em expansão que manipula e modifica os estímulos de modo a promover e facilitar a capacidade adaptativa do homem. A adaptação é a meta da enfermagem ${ }^{5,6}$.

A maneira como o indivíduo responde aos estímulos caracteriza seu comportamento, o qual irá refletir o uso de mecanismos de enfrentamento. Dessa forma, ao observar o comportamento das pessoas em relação aos modos adaptativos, a enfermeira poderá identificar respostas adaptativas ou ineficientes em situações de saúde e doença7.

Portanto, pretende-se neste estudo descrever e analisar os comportamentos e percepções relatados pelas mulheres com câncer de mama em relação a sua sexualidade dentro dos três modos adaptativos que foram verbalizados pelas participantes deste estudo.

\section{Modo Autoconceito}

0 modo Autoconceito é composto de crenças e sentimentos sobre si mesmo realizado em um determinado momento. Enfoca os aspectos psicológicos e espirituais do sistema humano. Tem como componentes o eu físico e o eu pessoal. 0 eu físico abrange a suas atribuições físicas, aparência, função, sexualidade e estado de saúde e de doença; enquanto o eu pessoal é uma avaliação individual de suas próprias características, expectativas, valores e méritos ${ }^{8}$.

Pode-se perceber que o aspecto autoconceito traz diversas situações que podem influenciar na sexualidade, mais pela terapêutica do que pela doença propriamente dita, uma vez que todos os tratamentos aos quais as mulheres com câncer de mama são submetidas deixam marcas em seus corpos e indisposição física, alteram o humor e dificultam a estabilidade emocional.

A Radioterapia pode alterar a autoimagem da mulher, pois frequentemente causa alterações na pele, podendo, nos casos mais graves, levar ao aparecimento de úlceras. Tudo isso acarreta um declive na autoestima da mulher, deixando-a triste e ansiosa ${ }^{9}$.

A radioterapia também provoca uma queimaçãozinha, que depois vira uma casquinha que incomoda, mas eu enfrentava. M4

A quimioterapia tem uma repercussão generalizada em todo o organismo humano, pois as drogas administradas acabam por atingir também células saudáveis do corpo, prejudicando a fisiologia geral ${ }^{3}$. 0 tratamento com quimioterápicos deixa as mulheres mais debilitadas. Seus efeitos adversos podem ser imediatos ou tardios e incluem principalmente: náuseas, fadiga, sonolência, mal-estar e fraqueza, que levam a uma indisponibilidade física. Outros efeitos adversos relevantes são a alopecia e o ganho de peso. Como pode ser observado na fala de diversas mulheres, a alopecia altera a autoestima e autoimagem da mulher. Com a alteração na sua aparência física, as relações sociais são afetadas.

Eu fiquei muito triste quando meu cabelo começou a cair porque foi justamente na formatura do meu filho, no dia do baile. Meu cabelo era por aqui, era channel quando eu fui ao banheiro que eu passei a mão, que peguei assim ele caiu. Ai bateu uma tristeza que não dá nem para explicar; é horrivel eu chorei muito [...] engordei por causa da quimio, engordei $10 \mathrm{~kg}$, tive que trocar todas as minhas roupas. M1

Dentre os tratamentos, o procedimento cirúrgico é o mais agressivo e que mais afeta a autoimagem e autoestima destas mulheres. Prado ${ }^{10}$ cita em seu trabalho que, apesar da existência de tratamentos quimioterápicos e radioterápicos, a mastectomia ou retirada da mama, nos seus diversos tipos, é o tratamento mais escolhido. A mama na mulher é um símbolo de feminilidade, de beleza, de eroticidade e de identificação do sexo; por isso perdê-la resulta na alteração negativa de sua imagem corporal. A retirada desse órgão representa uma limitação estética e funcional, que provoca imediata repercussão física e psíquica, constituindo um evento traumático para a maioria das mulheres.

Lá no hospital mesmo, quando eu tirei aquela faixa que eu vi, eu fiquei muito triste, muito mesmo, aquilo ali foi muito ruim, aí você precisa trabalhar sua cabeça de novo; eu fiquei uma semana mal, chorando muito [...] eu ficava imaginando, eu sem meus seios, foi muito difícil, até hoje é muito difícil. M2

Na verdade agente se sente muito mutilada. M1

Quanto à sexualidade, foram encontradas algumas dificuldades. Nos primeiros dias após a cirurgia algumas tiveram dificuldade em se vestir e ir a alguns locais públicos, mas com o tempo acabaram encontrando soluções para resolver esse problema. Olhar-se nua diante do espelho ou mostrar o corpo e o lugar da cirurgia para o companheiro tornou-se uma tarefa árdua e dolorosa para uma das mulheres entrevistadas. A mudança de posição na hora da relação também foi percebida. Apesar desses percalços, as mulheres relatam não terem perdido o prazer nem deixado de ter relação. 
Eu achei que ele não precisava me ver assim só por ele ser o meu marido, porque eu acho que o homem é muito de ver, então se ele não ver, ele vai só ficar pensando, mas ele não vai se chocar. M2

Eu tenho cicatrizes e algumas dessas cicatrizes me incomodavam um pouco, por isso dificilmente eu tomava banho na frente de alguém ou ficava exposta nua na frente de alguém por causa das cicatrizes das cirurgias anteriores. M4

Com relação às novas atitudes e posturas sexuais adotadas, a maior parte das entrevistadas que voltaram a manter relacionamento sexual após a doença e tratamento referem mudanças na maneira de se comportar durante 0 ato sexual, adotando um compor tamento de esconder o seio por vergonha do parceiro ${ }^{11}$.

\section{Modo Desempenho de Papéis}

0 Modo Desempenho de Papéis é o conjunto de expectativas sobre como uma pessoa ocupa um papel na sociedade. Consitui-se em uma necessidade social de se saber quem é em relação aos outros. Podemos observar o papel que a mulher adota em função do próprio gênero, do papel social como mãe e esposa e de suas atribuições profissionais.

As relações de gênero estiveram presentes no desenrolar de cada fase da doença e no tratamento, sendo que os papéis sexuais se mantiveram dentro dos padrões de nossa cultura ${ }^{9}$. As mulheres reforçam atitudes que representam expectativas culturais para o gênero feminino, como atitudes de conforto, de acalmar e dizer que tudo iria acabar bem.

No que diz respeito ao aspecto social, percebemos que, mesmo diante de uma situação de crise como o câncer, a mulher preocupa-se em realizar seu papel imposto pela sociedade. Encontramos algumas alteraç̃es relacionadas ao gênero, tanto masculino como feminino, nas quais a doença pode levar a comportamentos não tão esperados socialmente, podendo haver uma inversão de papéis. Mesmo nos tempos de hoje, infelizmente ainda se pode perceber atitudes preconceituosas. Dentre as mulheres entrevistadas nesta pesquisa, nenhuma relatou abandono pelo parceiro, nem divórcio ou separação durante o tratamento do câncer e até 0 momento da entrevista.

A mulher não pode ficar doente, ainda mais quando a gente tem filhos, não pode deitar na cama e ficar lá: 'Ah, agora eu estou doente', não podel Você não tem tempo para isso [...] Por que para minhas filhas eu não queria demonstrar fraqueza, até nas horas que eu estava assim caída eu ficava quietinha, ficava no meu canto eu estava sentindo tudo aquilo, mas eu não queria passar para elas. M2
Quando a mulher fica doente, ela acaba sendo obrigada a abandonar algumas atitudes e tarefas que são impostas ao sexo feminino na nossa sociedade, causando certo desconforto por imaginar que está deixando de realizar o seu papel enquanto mulher.

Dentre os papéis femininos determinados pela sociedade para a mulher, o cuidado com a casa é de sua responsabilidade, assim como a educação e criação dos filhos e o bem-estar da família. Sendo a administradora da casa e se preocupando com o bem-estar de todos, mesmo quando ela adoece, continua se preocupando com todos os familiares. A mulher em nossa sociedade é tida como sexo frágil, aquela que deve ser protegida e afastada dos perigos. Porém, as mulheres mostram-se fortes, decididas a vencer a doença e a enfrentar qualquer coisa para se restabelecerem fisicamente, retomarem seu papel de esposa e cuidar de todos os membros da família, ${ }^{9}$.

0 câncer de mama associa-se ao estresse psicológico não apenas na mulher, mas também em seu parceiro, sendo que "os cônjuges de mulheres com câncer de mama podem referir depressão, alterações do sono, disfunções sexuais e dificuldades no ambiente de trabalho"13.

Então quando estourou essa bomba na nossa vida, ele ficou arrasado, acabado, porque ele tinha medo de me perder. M4

Eu vi o corpinho dele tremendo, eu o vi chorando, ele estava desesperado como eu [... ] toda hora ele dizia isso vai passar, isso vai passar. Mas ele chorava muito, ele chorava mais do que eu. M5

Eu chorava principalmente quando meu marido não estava em casa, por que eu não queria que ele visse, senão ele ficava triste. M5

Eu ficava muito preocupada em ver minha mãe aqui na minha casa de cabeça baixa nos cantinhos e meu marido também por que ele falava: não, tá tudo bem, mas eles estavam destruídos por dentro. M4

Outro aspecto a ser estudado é a maneira como a mulher se sente vista perante a sociedade. As relações sociais são profundamente abaladas, já que o constrangimento de estar com uma doença estigmatizante leva a mulher a se afastar do seu convívio social ${ }^{14}$.

Eu perdi uns três cursos porque a minha coordenadora achava por bem que eu não fosse porque eu estava doente, ela achava que eu não estava com cabeça, mas ela se enganou, porque eu estava bem [...] mas eu não gostei, eu senti uma 
certa discriminaçãozinha, ela estava me deixando de canto por achar que eu não estava capaz. M5

As pessoas lá também me olhavam de lado, lá vai a coitada [...] eu sentia os outros me olhando com aquele preconceito, tipo: ah, tá com câncer, vai morrer. M4

0 preconceito que existe em relação ao câncer de mama é algo que inviabiliza grande parte das elaborações das mulheres acerca do câncer ${ }^{15}$. 0 afastamento de algumas pessoas e as situações de constrangimento, que começam a ser frequentes, normalmente estão relacionadas à falta de aceitação pelas pessoas com as quais convivem.

\section{Modo Interdependência}

0 Modo Interdependência é o comportamento relativo às relações de interdependência de indivíduos e grupos. Concentra-se no relacionamento de pessoas, suas finalidades e razão. Envolve vontade e capacidade de dar e receber afeto, respeito e valor aos outros e aceitá-los.

Ao serem questionadas sobre sua sexualidade, as mulheres entrevistadas frequentemente relataram situações nas quais seus respectivos esposos estavam ao seu lado, auxiliandoas, oferecendo carinho e apoio. Importante observar que elas não enfatizavam a relação sexual em si, mas pequenos gestos de demonstração de carinho e afeto eram o que alimentava sua autoestima e faziam-nas sentir que tudo estava bem. Essas mulheres revelaram uma força interior muito forte, mostraram empenho em manter o psicológico sempre positivo, afastandose de ideias tristes e deprimentes. Por aceitarem sua nova imagem, elas conseguem manter a harmonia na relação. 0 parceiro teve importante papel, pois sua presença ajudou a mulher a se restabelecer psicologicamente.

Eu acho que com a doença ele ficou melhor ainda mesmo, ele ficou mais companheiro, mas compreensivo, sabe. M2

Por isso que eu estou falando para você que eu sou uma felizarda, depois que descobri esse problema, eu descobri que meu marido me ama mesmo [... ] em relação a minha vida sexual não mudou nada, por que eu não me sinto assim horrorosa, na minha cabeça está tudo bem [...] mas a gente tem que permitir que a família nos ajude, por que às vezes seu marido quer te ajudar, mas você não deixa, você se tranca, então a gente tem que se deixar ajudar. M4

Alguns autores vêm constatando e enfatizando que 0 relacionamento sexual depende muito de como era antes da doença, podendo haver ausência de alterações no nível do relacionamento sexual, como alterações positivas e alterações negativas, relacionadas com o tipo de relacionamento anterior. Aquelas mulheres com bom relacionamento com o parceiro tendem a continuar da mesma forma ${ }^{9,11}$.

Não teve isso de dizer assim: não tô mais a fim, acabou o tesão. Na cabeça dele não tem isso. Então eu fico bem tranquila com relação a isso por que eu sei que não mudou. [...] ele me vê da mesma maneira que ele me via antes. Com peito feio não mudou, na cabeça dele eu tenho certeza que não mudou nada. M1

Barbosa $^{16}$, em sua pesquisa com 30 mulheres, refere que $93 \%$ das mulheres sentiram-se apoiadas pelo companheiro ao longo da doença e $80 \%$ afirmam que esse apoio influenciou a forma de viver a sexualidade.

Com certeza, conhecer a percepção de seu companheiro e sentir-se aceita auxilia muito esse processo. A segurança que as mulheres sentem com 0 apoio de seus companheiros deixa-as seguras e abre caminho para que elas possam restabelecer sua autoconfiança e autoestima.

Mulheres que não mantinham relacionamento afetivosexual antes da doença passaram a se afastar do sexo oposto, por adotarem uma postura de descrença com relação a novos relacionamentos, temendo frustrar o parceiro e sofrer rejeição pela condição de "mutiladas"11. Nesse estudo havia apenas uma participante que estava solteira e ela contradiz essa informação

\section{Se eu tiver que conhecer uma pessoa ele vai ter que me aceitar do jeito que eu sou, e eu tenho que me gostar para que uma pessoa goste de mim, então eu não tô preocupada em agradar ninguém. M3}

A qualidade do relacionamento existente entre o casal será responsável não só pelo alcance e manutenção da estabilidade emocional da mulher, mas também pelo retorno do interesse sexual em uma fase mais tranquila da doença. Após a cirurgia e com a estabilidade da doença, o casal volta a se interessar pela vida sexual e começa a se preocupar com o relacionamento sexual de ambos ${ }^{17}$.

0 relacionamento marital, quando existente, é considerado como fundamental para a reestruturação da integridade da mulher. Nesse momento em que ela se sente diminuída na sua feminilidade, atração e sexualidade, a presença do companheiro se torna imprescindível para esta reestruturação ${ }^{14}$. Isso foi muito bem retratado nesta pesquisa porque saber que seus maridos estavam ao seu lado e que podiam contar com sua ajuda e dedicação foi um aspecto que facilitou a superação da doença dessas mulheres.

Isso me ajudou bastante; a família, seu marido, sempre estar ao seu lado te ajuda muito porque você tem que sentir isso, você precisa sentir que é querida que está amparada. M2 
Meu marido ligava toda hora e dependendo da minha voz ele sabia que eu não tava bem e vinha ficar comigo. M1

0 apoio não só do marido e dos filhos, mas também de familiares e amigos próximos foi identificado como um fator que influencia na superação dessa fase, o apoio emocional foi relatado como um suporte que as fortaleceram e as auxiliaram no enfrentamento da doença.

Durante todo o processo da doença, o significado do suporte social para a mulher com câncer de mama se reveste de importância, pois ela se vê sendo ajudada para não desistir, 0 afeto familiar permite à mulher manter uma certa estabilidade para lutar contra a doença, conseguindo suprir suas carências emocionais e alcançando uma melhor aceitação e orientação comportamenta $\left.\right|^{14,18}$. Nesse sentido, a família é importante, oferecendo palavras de encorajamento, ajuda física e emocional.

Minhas filhas me levavam água, suco, água de coco [...] onde eu estava tinha alguém comigo querendo saber o que eu queria, limpando meus vômitos. M1

Essa foi minha força, eu me agarrei às pessoas que eu gosto minha mãe, meu pai, minhas irmãs, a minha família. M4

O apoio, o carinho da família e das pessoas que estão ali no dia a dia, os vizinhos os amigos foi fundamental. Isso me fez muito bem e me ajudou a passar essa fase. M5

Os profissionais de saúde também foram considerados elementos importantes no enfrentamento da doença, quando informavam sobre a doença e sua evolução, bem como quando encorajavam e confortavam a mulher ${ }^{18}$.

Eu conversei com o médico e ele falou: olha você é uma sortuda, levanta a mão para o céu e agradeça, aí eu acreditei e me agarrei nisso. M4

Eu confio muito no meu médico. Os meninos da quimio (equipe de enfermagem) são uns anjos, eles me abraçam me beijam. Acho que porque eles sabem o que você vai passar então eles te abraçam te beijam desde a primeira até o fim do tratamento, e isso ajuda muito. Eles me cobrem de carinho e atenção. Tudo isso te deixa melhor. M1

Essas mesmas autoras apontam para o importante significado atribuído pela mulher com câncer de mama quando encontra outras mulheres que vivem ou vivenciaram a mesma experiência. Saber que não estão sós, que outras pessoas já passaram por isso ajuda muito e conforta suas mentes $^{18}$.

Eu peguei uma revista Veja e abri numa reportagem que tinha uma mulher que recebeu uma noticia igual a mim, então eu vi a historia dela que era a minha, ela também ficou sem chão como eu me senti, aí depois passou [...] eu comprei um livro que fala de câncer de um médico muito bem conceituado que também teve câncer, aí eu fiquei lendo. M2

Eu não vi isso como o fim, eu tenho uma irmã que passou por isso há dois anos e hoje em dia nem parece que ela teve isso. M3

Observar que outras pessoas já passaram pela mesma situação traz um conforto às mulheres. Isso Ihes mostra que existe um caminho para superar esta fase.

\section{CONSIDERAÇÕES FINAIS}

Durante as entrevistas, as mulheres ficaram bem à vontade para falar o que para elas era mais importante. Foi possível perceber que elas tinham uma visão segura de sua sexualidade e englobavam vários valores nesta categoria, principalmente a relação consigo mesma e com os outros.

Quanto ao autoconceito, as mulheres evidenciaram sentimentos de tristeza, ansiedade, vergonha, exclusão e mutilação devido aos efeitos colaterais das drogas quimioterápicas, da radioterapia e da cirurgia. Podemos observar a mudança da imagem corporal, principalmente pela alopecia, ganho de peso, cicatrizes e perda da mama.

Em relação ao desempenho de papéis foram observadas algumas alterações relacionadas principalmente ao gênero, mas não foi observado nenhum desajuste sexual. As mulheres relataram a importância de se manter forte para cuidar dos filhos e esposo, a inversão de papéis com os homens e as situações constrangedoras no local de trabalho como ser afastada de suas funções, a discriminação e o preconceito.

Já quanto à interdependência, podemos ver que, mesmo sofrendo uma crise no início da doença, foi identificado como um facilitador do restabelecimento sexual do casal o apoio do marido. Outras pessoas também têm papel importante na adaptação a esta nova situação, tais como filhos e família, bem como os profissionais de saúde e outras pessoas que já vivenciaram o câncer de mama.

Pode-se afirmar que as mulheres sofreram problemas para sua adaptação à nova realidade. A aceitação da nova imagem corporal, os sentimentos negativos, a dor, a tristeza e o medo estão presentes em suas falas, mas o apoio das pessoas próximas é fundamental para sua adaptação. 
Consideramos que a utilização do Modelo Adaptativo de Roy para análise foi apropriado para este grupo de pacientes e para a situação vivenciada por elas, tendo permitido apreender as alterações relacionadas aos modos adaptativos e, visualizar de forma concreta quais os focos para as intervenções de enfermagem.

Deseja-se que esse estudo sirva como um incentivo para que os profissionais enfermeiros despertem para a importância de dedicar mais atenção e conversar abertamente com suas clientes, pois, conhecendo melhor a realidade vivenciada pelas mulheres com câncer, é possível proporcionar um tratamento mais humanizado e enriquecedor. Além disso, a teoria de Roy pode auxiliar também no planejamento do cuidado de uma forma específica a estas mulheres, uma vez que tem entre seus objetivos atingir metas de enfermagem.

\section{REFERÊNCIAS}

1. Ministério da Saúde(BR).Instituto Nacional do Câncer- INCA. Estimativas 2012: incidência de câncer no Brasil. Rio de Janeiro; 2011; [citado 2012 mar 20].Disponível em:<http://www.inca.org.br/estimativas/2012>.

2. Lima ALP, Rolim NCOP, Gama MEA, Pestana AL, Silva EL, Cunha CLF. Rastreamento oportunístico do câncer de mama entre mulheres jovens no Estado do Maranhão, Brasil. Cad Saude Publica. 2011; 27(7): 1433-39.

3. Melo AS, Carvalho EC, Haas VJ. Características definidoras validadas por especialistas e as manifestadas por pacientes: estudo dos diagnósticos disfunção sexual e padrões de sexualidade ineficazes. Rev Latino-Am Enfermagem. 2008; 16(6): 951-58.

4. Manganiello A, Hoga LAK, Reberte LM, Miranda, CM, Rocha CAM. Sexuality and quality of life of breast cancer patients post mastectomy. Euro J Oncol Nurs. 2011; 15: 167-72.

5. Leopardi MT. Teorias em enfermagem: instrumentos para a prática. Florianópolis : Papa-Livros; 1999. 226 p.

6. Mcewen M, Wills EM. Bases teóricas para enfermagem. Porto Alegre: Artmed; 2008. 576 p.

7. Freitas MC, Oliveira MF.Assistência de enfermagem a idosos que realizam cateterismo cardíaco: uma proposta a partir do modelo de adaptação de Calista Roy. Rev Bras Enferm. [on-line]. 2006; 59(5): 642-46.

8. Brandão de Carvalho LAL, Cavalcante MV, Venícios de Oliveira LM. Adaptação psicossocial do adolescente póstrasplante renal segundo a teoria de Roy. Invest Educ Enferm. 2005; 23(1): 68-77.

9. Gradim CVC, Almeida AM. Sexualidade de casais que vivenciaram 0 câncer de mama: quebrando mitos. Rev Bras Sex Hum. 2006; 17: 201 07.

10. Prado JAFA. Supervivência: novos sentidos na vida após a mastectomia. [dissertação]. Florianópolis: Centro de Filosofia e Ciências Humanas, Universidade Federal de Santa Catarina; 2002.
11. Rossi L, Santos MA. Repercussões psicológicas do adoecimento e tratamento em mulheres acometidas pelo câncer de mama. Psicol Cienc Prof. 2003; 23(40): 32-41.

12. Araújo IMA, Fernandes AFC. Os significados do diagnóstico do câncer de mama para a mulher. Esc Anna Nery. 2008 dez; 12(4): 664-71.

13. Conde DM, et al. Qualidade de vida de mulheres com câncer de mama. Rev Bras Ginecol Obstet. 2006; 28(3): 195-204.

14. Almeida RA. Impacto da mastectomia na vida da mulher. [monografia de especialização em Psicologia Hospitalar e da Saúde]. Rio de Janeiro: Santa Casa de Misericórdia do Rio de Janeiro; 2007.

15. Vieira PC, Lopes MHBM, Shimo AKK. Sentimentos e experiências na vida das mulheres com câncer de mama. Rev Esc Enferm USP. 2008; 41(2): 311-16.

16. Barbosa JRG. A sexualidade nas mulheres mastectomizadas. [monografia de Licenciatura em Enfermagem]. Porto: Faculdade de Ciências da Saúde, Universidade Fernando Pessoa; 2008.

17. Pádua EA. Câncer de mama não impede a prática sexual. [on-line] 2006; [citado 2011 jan 12]; Disponível em: http://www.wmulher.com.br/ print.asp?id_mater $=3134 \&$ canal $=$ sexo.

18. Ângelo M, Bergamasco RB. 0 sofrimento de descobrir-se com câncer de mama: como o diagnostico é experienciado pela mulher. Rev Bras Cancerol. 2001; 47(3): 277-82. 